\title{
Expert System To Detect Human's Skin Diseases Using Forward Chaining Method Based On Web Mobile
}

\author{
Jenie Sundari ${ }^{1}{ }^{*}$ Hamimah $^{2}$, Popon Handayani $^{2}$, Yunita ${ }^{1}$, Ibnu Dwi Lesmono ${ }^{3}$, Mulia \\ Rahmayu ${ }^{2}$, Paramita Kusumawardhani ${ }^{4}$, Yusnia Budiarti $^{1}$, Fadilah ${ }^{4}$, Nurhayati ${ }^{4}$ \\ ${ }^{1}$ STMIK Nusa Mandiri, Information Technology Program Jakarta, Indonesia \\ ${ }^{2}$ STMIK Nusa Mandiri, Information System Program Jakarta, Indonesia \\ ${ }^{3}$ AMIK BSI Purwokerto Manajemen Informatic Program Purwokerto, Indonesia \\ ${ }^{4}$ ABA BSI Jakarta, English Program Jakarta, Indonesia
}

\begin{abstract}
Skin is a sense of touch in humans' body which one of its functions is to feel the touch. Another function of the skin is to release the residual substances such as sweat. This part of the human body is very sensitive, easy to get hurt, and feels a sense of sensitivity. Human skin consists of epidermis and dermis. Skin diseases can be caused by a decrease in the immune system, allergies, viruses, or other causes. Skin disease is generally caused by a less guarded hygiene, bacteria, viral, allergic reactions, and low body resistance. If the cause of skin disease is only due to a lack of maintaining cleanliness, it can be prevented by changing lifestyles to be cleaner and healthier. Especially in Indonesia which is a tropical country, where the humidity is very high and can increase the development of bacteria on the skin. In another situation, not all people understand skin diseases for treatment or prevention. By the reason, The Forward Chaining Method is made to provide information about diagnoses of several skin diseases and produces conclusions. The existence of this expert system application makes it easy for people to get any information about skin diseases
\end{abstract}

\section{Introduction}

Skin is a human-body part which is the widest area that arranges body and system that covers all body. Skin is the part which can accept the stimulus such as touching, feeling hurt and others influence from outside. Based on the most important thing of covering the organs inside and under it, it is important to protect the skin-health from the very beginning. Many skin diseases can be factored by many aspects such as climate changing, environment

\footnotetext{
${ }^{1}$ Corresponding author: jenie.jni@nusamandiri.ac.id
} 
surrounding and a bad-self health which is caused by bacteria, viruses, self immune, allergic reaction, and others. Skin defining cannot be done carelessly because it can endanger the skin care and handling. Based on the reasons, it is important to consult about skin problems to the doctors or the experts.

Skin diseases in Indonesia can be high categorized and make a serious problem. It can be happened because there are still many Indonesian citizens who do not really care with the skin diseases. The citizens' ignorance can cause skin diseases spread out quickly. Bad environment and habits, such as climate changing, viruses, bacteria, allergic, self-immune, etc. are some factors which can cause skin diseases. [1]

Indonesian health profile in 2008 showed that the distributions of outpatients patients based on International Classification of Diseases-X (ICD-X) in Indonesia's hospitals, based on skin diseases, are about 115.100 visitors with 64.557 new cases. Skin diseases increased up to the third grade from the ten-most diseases in outpatients' patients around Indonesia, 192.414 visitors with 48.576 new cases in 2011. [2]

The idea behind creating an expert system is that it can enable many people to benefit from the knowledge of one person - the expert. It is done in order to simulate the judgment and behavior of a human that has expert knowledge and experience in a particular field is expert system. [3]

To apply forward chaining inference techniques which are applied, the data and facts has been obtained so it can be made to conduct the research process that will provide a conclusion or solution based on a set of data and facts. By using inference techniques are also opportunities to get a more specific conclusion can be easily obtained. [4]

\section{Literature review}

The expert system for memory losing disease is should be appropriate to the rules and facts. It can also be used based on case to save the cases to compare between the new cases with the previous case. It is done by discussing the different approach by focusing to all information about losing memory. Different symptoms and caused of losing memory in different ages group can make different way to avoid all losing memory diseases. The patients can be helped to get the advices needed about the symptoms based on their nervous system by using the expert system. [5]

In this study, an automated diagnosis system to detect breast cancer based on data preprocessing and Bayesian networks is presented. This study shows that Bayesian networks in the diagnosis of the disease according to the nature of the algorithms work very well. Relief algorithm is also used to reduce the number of the database features that shows how it can produce useful results in combination with Bayesian network classifier. Also, we tried to show that the classifiers can reach to a certain extent of accuracy for this database. Thus for obtaining more accuracy we should do enough preprocessing on the data, resolve missing data and data unbalancing phenomenon for the data. Finally, the significant accuracy for diagnosing breast cancer disease by using 3 -fold cross validation test method can be obtained. [6]

This paper has presented an expert system for rickets diagnosis, which provides the patients with the diagnosis, recommendation and treatment; based on the expert system knowledge base and data collected from the patients. The aim of the proposed expert system was to recognize the symptoms of the disease by the user to enable him/her to identify diseases and causes of rickets. This expert system saves the patient's time and effort by allowing the patient to diagnose rickets seamlessly and easily through a simple user interface, so often is dispensed with the traditional diagnosis. [7]

The web based expert system (WES) is created to diagnose the skin disease in Pakistan especially in flood prone areas. The system has the newest knowledge to tract the previous 
disease based on the skin expert, medical students and pharmacists. The system is developed by using Java application and forward chaining inference system. The result of this research is to diagnose more than 13 skin diseases. [8]

Online system to diagnose skin disease in children is created and developed. The system is created by using forward chaining inference system so parents can get the information about the skin disease happened to their children then suggest the suitable medicine related to the skin disease itself. [9]

The lungs are one of the vulnerable respiratory organs. The purpose of this research is to implement decision tree and dempster shafer method on lung disease diagnosis and measure the accuracy of the system. The symptom was searched using forward chaining decision tree and the diagnosis was calculated using dempster shafer method. [10]

The development cycle of an expert system is shown in Figure 5. Referring to Figure 5, after selecting the orthopedic domain, knowledge was acquired by interviewing an orthopedic surgeon. The knowledge is all about the different patient's problems, such as shoulders, knees, hips, feet, thumbs, and wrists. The knowledge base is incomplete, and has six different problem areas and 370 rules with certain orthopedic diseases, but it could be updated with new symptoms and diseases. [11]

Expert System on the organization was aimed at adding value, increasing productivity as well as the area of managerial can make decisions quickly and accurately. The benefits of the expert system was able to diagnose quickly and accurately to the symptoms of the disease caused and it was expected to help the farmers in anticipating many losses caused by disease. Required accuracy and the accuracy of the counting in diagnosing the symptoms of the disease is in order to summarize the results by using forward chaining method. [12]

This paper describes Expert System (ES) for online diagnosis and prescription of redeye diseases. The types of eye diseases which can be diagnosed with this system are called Red-eye diseases. It is rule based web-supported expert system, assisting ophthalmologists, medical students doing specialization in ophthalmology. Researchers as well as eye patients have computer know-how. System was designed and programmed with Java Technology. The expert rules were developed on the symptoms of each type of Red-eye disease, and they were presented using tree-graph and inferred using forward-chaining with depth-first search method. [13]

In this research, the expert system is created. It is created to decide about kinds of eyeglass lens using forward chaining method. Forward chaining method is started by using preliminary information (preliminary symptom) and it moves forward to adjust to the latest information. It is done in order to give the solutions based on eyeglass lens. [14]

\section{Research method}

\subsection{Inference method}

The Inference Engine forms the heart of the expert system; the knowledge base serves as the brain of the expert system. The inference engine chums through countless potential paths and possibilities based on some combinations of rules, cases, models or theories. Some rules such as predicate logic mimic human reasoning and offer various mathematical arguments to any query. Two methods of inference often are used, forward and backward chaining; forward chaining is a top down method which takes facts from satisfied conditions and backward chaining is a top down method which takes facts from satisfied conditions in rules. [15] 


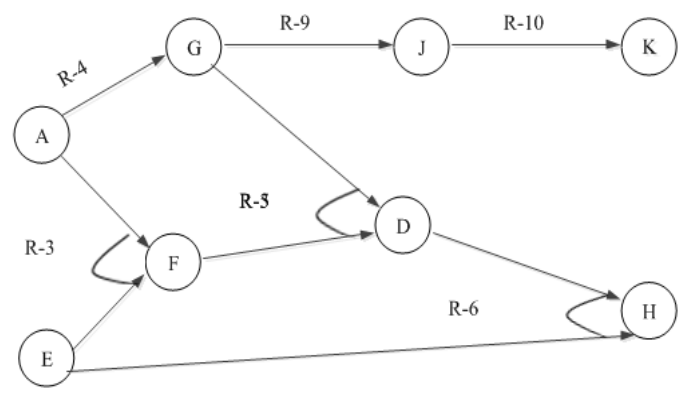

Fig. 1. How the forward chaining inference machine works

\subsection{Decision tree}

Decision Tree is a tree structure like a flow-chart, in which the rectangular boxes are called the node. Each node represents a set of records from the original data set. Internal node is a node that has a child and leaf (terminal) node is nodes that don't have children. Root node is a topmost node. For finding the best way to distinguish a class from another class, the decision tree is used. [16]

\section{Result \& Discussion}

\subsection{The expert}

The table of expert consists of facts obtained from an expert, science, research and experiences in diagnosing skin diseases. The following are the data obtained from the experts:

1. Table of skin disease symptoms

Table 1. Table of skin disease symptoms

\begin{tabular}{|l|l|}
\hline \multicolumn{1}{|c|}{ Code } & \multicolumn{1}{c|}{ Symptoms } \\
\hline G01 & an itchy rash \\
\hline G02 & open sores or lesions \\
\hline G03 & burning skin \\
\hline G04 & exfoliation or dandruff on the mustache, beard and eyebrow area \\
\hline G05 & bubbles on the skin with yellowish liquid \\
\hline G06 & 0.5 centi-meter bubble which quickly swells and pops easily \\
\hline G07 & cracked skin such as blistered skin exposed to cigarette burns \\
\hline G08 & a circular reddish or silvery rash \\
\hline G09 & scaly skin \\
\hline G10 & skin inflammation/dermatitis \\
\hline G11 & easily irritated if exposed to rubbing \\
\hline G12 & raised bumps or wrinkles \\
\hline
\end{tabular}


2. Table of skin disease types

Table 2. Table of Skin Disease Types

\begin{tabular}{|l|l|}
\hline \multicolumn{1}{|c|}{ Code (s) } & \multicolumn{1}{c|}{ Type of Skin Disease } \\
\hline P01 & Dermatitis Seboroik \\
\hline P02 & Vitiligo \\
\hline P03 & Keloid \\
\hline P04 & Tinea Korporis \\
\hline P05 & Impetigo Bulosa \\
\hline P06 & Psoriasis \\
\hline P07 & Seborcheic Keratosis (Keratosis Seboroik) \\
\hline P08 & Dyshidrotic Eczema \\
\hline P09 & Angioedema \\
\hline P10 & Kista Sebaceous \\
\hline
\end{tabular}

3. Decision tree

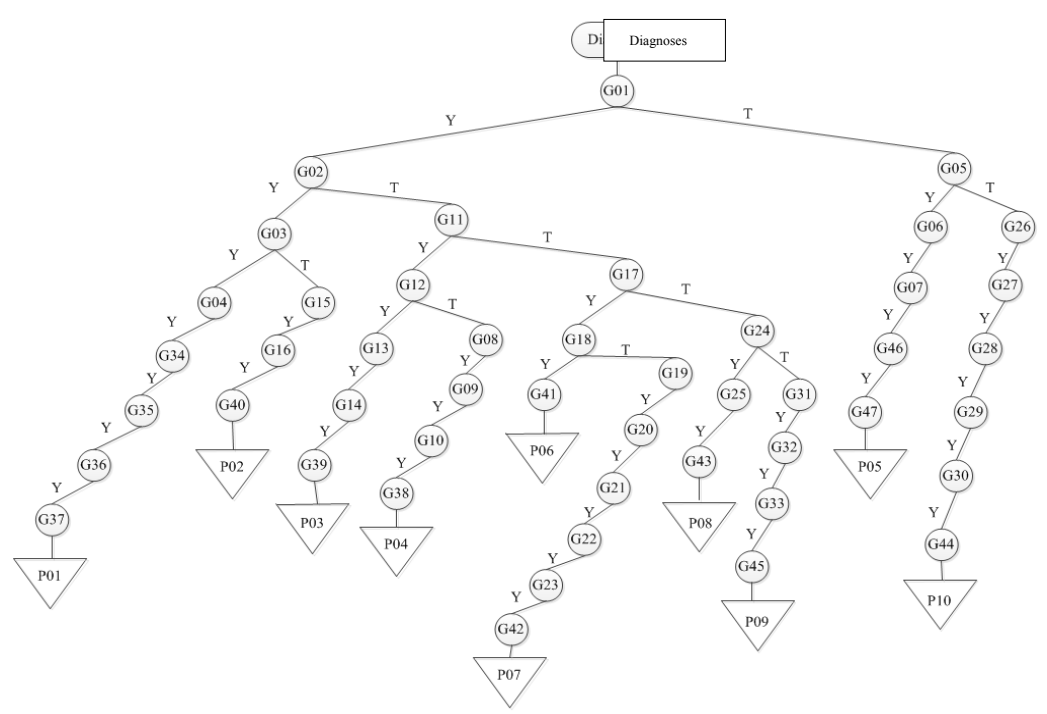

Fig. 2. How the forward chaining inference machine works

4. Implementation of Expert System Web

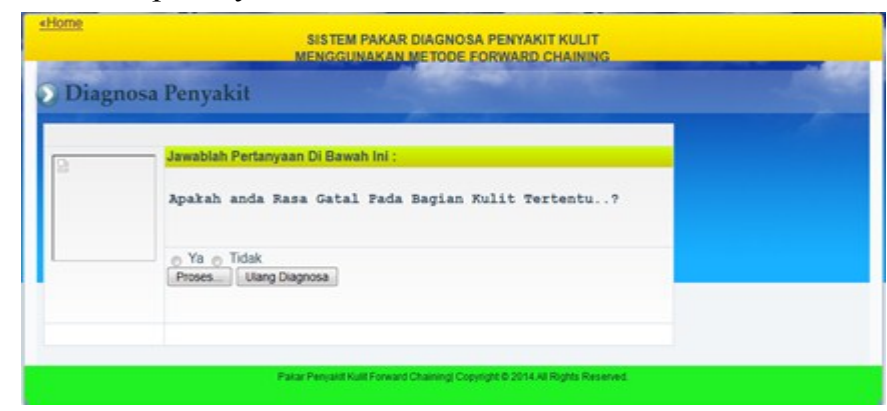

Fig. 3. Consultation page 


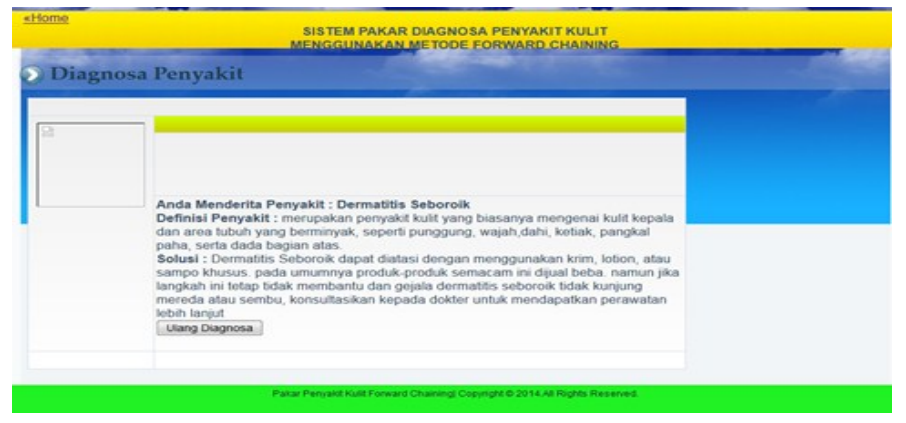

Fig. 4. Diagnosis result

\section{Conclusion}

From the analytical descriptions above, the following are the conclusions of this research:

The expert system could help the users (patients) to diagnose the suffered disease based on the selected symptoms by those who did a direct consultation.

The process of designing the expert system application program to diagnose skin diseases in humans includes several steps that must be considered such as knowledge acquisition, knowledge representation, and compilation of databases, inference machines, UML diagrams, interface design, implementation and testing.

The use of the forward-chaining method with the search process can be used to create an expert system for detecting human skin diseases.

\section{References}

1. Pardiansyah, R., Association Between Personal Protective Equipment With the Irritant Contact Dermatitis in Scavengers Faculty of Medicine, (Lampung University 2015).

2. Kementerian Kesehatan Indonesia, 2012. Profil Kesehatan Indonesia Tahun 2009. Jakarta: Kementerian Kesehatan RI

3. Shikhar Kr. Sarma, Kh. Robindro Singh \& Abhijeet Singh, An Expert System for diagnosis of diseases in Rice Plant International Journal of Artificial Intelligence, Volume(1): Issue(1) 26. (2010)

4. Baur Gregory R. \& Pigford D.V. 1990. Expert System for Business: Concept and Implementations, Boyd \&Fraser Publishing Company, Boston-USA (1990).

5. Sasmito WG, Bayu Surarso, Aris Sugiharo. Application Expert System of Forward Chaining and The Rule Based Reasoning For Simulation Diagnose Pest and Disease Red Onion and Chili Plant. ICISBC. (2011)

6. Fallahi Amir, Shahram Jafari. An Expert System for Detection of Breast Cancer using data Processing and Bayesian Network. International Journal of Advanced Science and Technology. Vol 34 September. (2011)

7. Al Rekhawi, Abdullah A Ayyad, Abu Naser. Rickets Expert System diagnoses and treatment. International Journal of Engineering and Information Systems. Vol 1 issue 4. (2017)

8. Amarathunga, EPWC Ellawala, GN Abeysekara, CRJ Amalraj. Expert System for Diagnosis of Skin Diseases. International Journal of Scientific \& Technology Research. Vol 4 issue 01. January (2015). 
9. Yusof M Munirah, Ruhaya A Aziz, Chew S Fei. The Development of Online Children Skin Disease Diagnosis System. International Journal of Information and Education Technology. Vol 3 no 2. April (2013)

10. Alfatah Muis Abdul, Riza Arifudin, Much Aziz Muslim. Implementation of Decision Tree and Dempster Shafer on Expert System for Lung Disease Diagnosis. Scientific Journal of Informatics. Vol 5 no 1. May (2018)

11. Zuhra Tul Fatima, Adnan Ahmed Arain, Mohsin Ali Tunio. An Implementation of Expert System for Orthopedic Patient Diagnosis. Quaid E Awam University Research Journal of Engineering Science\&Technology. Vol 15 no 1. Jan (2016).

12. Hayadi Herawan B, Kasman Rukun, Rizky Ema Wulansari, etc. Expert System of Quail Disease Diagnosis Using Forward Chaining Method. Indonesian Journal of Electrical Engineering and Computer Science. Vol 5 no 1. January (2017).

13. Dr Asghar Muhammad Zubair, Dera Ismail Khan, Muhammad Junaid Asghar. Expert System for Online Diagnosis of Red-Eye Disease. International Journal of Computer Science\&Emerging Technologies. Vol 1 issue 2. August (2010).

14. Pramesti Ari Atikah, Riza Arifudin, Endang Sugiharti. Expert System for Determination of Type Lenses Glasses Using Forward Chaining Method. Scientific Journal of Informatics. Vol 3 no 2. (2016)

15. Folorunso I O, Abikoye OC, Jimoh RG, Raji KS. A-Rule Based Expert System for Mineral Identification. Journal of Emerging Trends in Computing and Information Sciences. Vol 3 no 2. February (2012)

16. Saini Priyanka, Sweta Rai, Ajit Kumar Jain. Decision Tree Algorithm Implementation Using Educational Data. International Journal of Computer-Aided Technologies. Vol 1 no 1. April (2014). 